\title{
Design de personagens para séries de TV animadas: uma revisão integrativa
}

Character design for animation TV series: an integrative review

Tiago Ribeiro ${ }^{1}$ Milton Vieira ${ }^{2}$ Alice Pereira ${ }^{3}$ 


\section{Resumo}

A expansão recente das séries de animação brasileiras na televisão, fruto do incentivo de organizações públicas e privadas, apresenta um campo frutífero de atuação mercadológica e de pesquisa. Os personagens são, junto do roteiro, o principal ponto de contato do público espectador com a obra de animação. Tendo isso em vista, cabe investigar como tornar mais efetivo o desenvolvimento de personagens para séries animadas, levando em conta sua agradabilidade e engajamento. Este trabalho então propõe-se a iniciar uma série de pesquisas neste campo, o que torna necessário o desenvolvimento de uma revisão integrativa, para coletar o que já foi produzido de relevante, em termos científicos e empíricos, referente ao tema "desenvolvimento de personagens para séries animadas de TV". Os resultados apresentam tópicos que dizem respeito ao impacto cultural que os personagens provocam no público e os aspectos técnicos, visuais e psicológicos do desenvolvimento de personagens.

Palavras-Chave: animação; design de personagens; televisão; TV; séries de televisão

\section{Abstract}

The recent expansion of the brazilian TV animation series, due to the encouragement of public and private organizations, presents a fruitful field of merchandisign and research activities. Characters are, along with the script, the main point of contact of the public and an animation. With this in mind, it is worth investigating how to make more effective the development of characters for animated series considering its pleasantness and engagement. This paper pretends to start a series of researches in this field, which makes necessary to develop a integrative review to collect what relevant has been scientifically and empirically related to theme "character development for animated TV series". The results present topics concerning the cultural impact that the characters provoke in the public and the technical, visual and psychological aspects of character development.

Keywords: animation; character design; television; TV; TV series

ISSN: 1808.3129

1 tiago.oriebir@gmail.com

2 milton@cce.ufsc.br

3 acybis@gmail.com 


\section{INTRODUÇÃO}

A animações brasileiras ganham cada vez mais espaço na televisão nacional, fomentadas por leis e incentivos à produção, o que vem ocasionando um processo de mudança e expansão nos últimos anos. A sanção da lei 12.485, em junho de 2011, foi fator importante nesse processo, uma vez que estabelece para os canais de televisão (TV) por assinatura uma quantidade mínima de tempo de exibição dedicada somente a conteúdos brasileiros, sendo que ao menos metade deste conteúdo deve ser produzido por produtoras brasileiras independentes. Esta legislação vem promovendo um fortalecimento das produtoras de animação brasileiras.

Outro fator que evidencia este crescimento é o processo de internacionalização pelo qual a produção de séries de animação brasileiras estão passando. Séries como Princesas do Mar (2005), Peixonauta (2009) e Irmão do Jorel (2014) são idealizadas por brasileiros e alcançaram o mercado internacional, com níveis variados de representatividade. Este fenômeno também causa impacto em outros mercados por meio do surgimento de produtos licenciados, que geram renda e movimentação financeira - de acordo com a Associação Brasileira de Licenciamento (ABRAL), o Brasil é atualmente o sexto país com maior faturamento em licenciamento de marcas do mundo, tendo vivenciado uma constante de crescimento em faturamento nos últimos anos. (ABRAL, 2015).

Um dos fatores-chave para o sucesso de uma animação está nos personagens. Conforme Nesteriuk (2011, p. 180), o personagem talvez seja o elemento mais fundamental, dentre os aspectos principais de uma animação, chegando a ressaltar a própria etimologia dos termos "animação" e "personagem" para reforçar essa proximidade: anima (dar alma, vida) e persona (pessoa). Para White (2006, p. 30) não há sombra de dúvida quanto ao roteiro ser o mais importante ingrediente de qualquer filme, mas os personagens têm um grande papel quando esse script é animado. Além disso, levando em conta a dimensão do licenciamento, os personagens tornam-se o principal elemento de identificação do público com os produtos, agregando valor e aumentando a diferenciação em relação aos concorrentes (ABRAL, 2015). Seja pelo ponto de vista mercadológico ou pelo aspecto narrativo, é clara a importância dos personagens no desenvolvimento de uma série de animação; característica que, dada a nova realidade de expansão da produção nacional de animação, precisa ser investigada.

Desta maneira, tem-se o seguinte questionamento como foco de pesquisa deste estudo: Quais os conhecimentos necessários para realizar o desenvolvimento de personagens que integrem os atributos de agradabilidade e engajamento à narrativa, favorecendo o envolvimento do espectador com a série animada para TV?

Assim, o objetivo principal deste estudo foi dar início às pesquisas neste campo, a partir da categorização dos artigos científicos que existem acerca do tema "desenvolvimento de personagens para séries animadas de TV" por meio de uma revi- 
são integrativa e agregar conceitos que adicionem à esta discussão. Destarte, foram selecionados os seguintes objetivos específicos para tornar possível esta pesquisa: 1 - selecionar um grupo relevante de material bibliográfico sobre desenvolvimento de personagens, sob a perspectiva das séries animadas para televisão, tanto em bases científicas quanto de forma empírica; 2 - realizar a análise do conteúdo deste material; 3 - identificar os termos com mais recorrência na perspectiva deste assunto.

De acordo com Souza, Silva e Carvalho (2010), a revisão integrativa trata-se de um instrumento da prática baseado em evidências, sendo a mais ampla abordagem metodológica referente a revisões, permitindo a inclusão de estudos experimentais ou não com o intuito de alcançar uma compreensão completa do objeto analisado, combinando também dados de literatura teórica e empírica. Esta ampla mostra deve gerar uma perspectiva consistente e compreensível a respeito dos conceitos e teorias expressivos para a questão estudada.

Este estudo, de objetivo exploratório-descritivo, foi fundamentado no levantamento de artigos científicos em duas bases do portal Capes: Scopus e Web of Science, utilizando o ProKnow-C como ferramenta de investigação.

\section{Procedimentos metodológicos}

Esta pesquisa, conforme explícito em seus objetivos, dedica-se a levantar informações a respeito do tema proposto para em seguida fazer uma apresentação descritiva de todos os procedimentos e resultados alcançados, características que a define como uma pesquisa exploratória e descritiva, conforme Prodanov e Freitas (2013) estabelecem. No que diz respeito aos procedimentos técnicos utilizados na coleta destes dados, o caráter desta pesquisa é bibliográfico, sendo composto por uma investigação sistemática em conjunto com uma exploração empírica. O processo de investigação sistemática usa como ferramenta de busca e seleção o instrumento ProKnow-C, desenvolvido na Universidade Federal de Santa Catarina (UFSC), que fundamenta-se em rigorosa sistematização com o objetivo de minimizar a aleatoriedade e subjetividade no processo de levantamento do portfólio bibliográfico. (AFONSO et al., 2011). Para guiar este processo, foram levantadas nove etapas que constituem o ProKnow-C, para se fazer a seleção de artigos científicos das bases de dados, a saber:

Etapa 1: definição das palavras-chave selecionadas, de acordo com a aderência ao tema de pesquisa;

Etapa 2: escolha das bases de dados com maior relevância ao tema proposto para se fazer a busca;

Etapa 3: realização do teste de aderência das palavras-chave, buscando encontrar outros possíveis termos relevantes ou sinônimos que sejam pertinentes ao tema de pesquisa; 
Etapa 4: uso do gerenciador bibliográfico EndNote X7 para excluir artigos repetidos;

Etapa 5: busca, através da ferramenta Google Acadêmico, do número de citações de cada artigo, constatando assim sua relevância científica;

Etapa 6: verificar a relevância científica, quando não for possível confirmá-la através do número de citações, pela atualidade do artigo, de acordo com seu ano de publicação;

Etapa 7: leitura dos resumos dos artigos buscando identificação dos mesmos com o tema de pesquisa;

Etapa 8: exclusão dos artigos não disponíveis de forma integral;

Etapa 9: definição do portfólio bibliográfico em conformidade com o tema de pesquisa, por via da leitura integral dos artigos restantes.

Entende-se a próxima fase, exploração empírica, de acordo com a concepção estabelecida por Prodanov e Freitas (2013, p. 17), de que "Para a ciência, empírico significa guiado pela evidência obtida pela pesquisa científica sistemática.", ou seja, apenas depois de realizada a etapa de revisão sistemática será possível ter um melhor discernimento dos assuntos que tangem o tema de pesquisa, sendo então possível verificar livros, profissionais, práticas, empresas e outros materiais, impressos ou audiovisuais, que poderão colaborar com o portfólio de referências pertinentes para a pesquisa.

Os procedimentos metodológicos são apresentados no quadro a seguir, no intuito de permitir uma melhor visualização da sistemática de pesquisa.

Quadro 1 - Procedimentos metodológicos

\begin{tabular}{|c|l|}
\hline Etapa & \multicolumn{1}{|c|}{ Atividade } \\
\hline 1 & Definição das palavras-chave; \\
\hline 2 & Escolha de bases de dados relevantes; \\
\hline 3 & Teste de aderência com as palavras-chave; \\
\hline 4 & Exclusão de artigos repetidos; \\
\hline 5 & Verificação da relevância dos artigos, por meio de suas citações; \\
\hline 6 & Verificação da relevância dos artigos, a partir do ano de publicação. \\
\hline 7 & Seleção de artigos a partir da leitura de resumos; \\
\hline 8 & Exclusão de artigos não disponiveis integralmente; \\
\hline 9 & Seleção dos demais artigos por meio de sua leitura integral. \\
\hline Fonte: os autores.
\end{tabular}




\section{Resultados}

Na primeira etapa da análise, foram definidas as palavras-chaves que representassem os três eixos desse estudo. A primeira delas, character design ou character está relacionada ao objeto deste estudo, o desenvolvimento de personagens. A segunda palavra-chave, animation, está relacionada com o formato de realização do produto audiovisual - pesquisa-se o desenvolvimento de personagens para séries de animação e não séries de live action (termo utilizado para designar produções audiovisuais que são realizadas por atores reais, diferente das animações) ou filmes. A terceira palavra-chave television ou TV ou TV seri*, está ligada ao contexto de projeto do objeto de estudo: as séries para televisão. Utilizou-se o asterisco no radical de da última palavra-chave visando atingir mais variações nominais, da mesma maneira que optou-se por utilizar a lingua inglesa em todas as palavras.

Na segunda etapa, de escolha de base de dados, foi preciso levar em conta que se tratava de uma pesquisa multidisciplinar. Por isso, foi adotada inicialmente a biblioteca virtual da Coordenação de Aperfeiçoamento de Pessoal de Nível Superior (CAPES), que disponibiliza mais de 37 mil periódicos disponíveis em texto completo em 126 bases referenciais (CAPES, 2015). Entretanto, devido a ineficiência em recuperar artigos neste portal, optou-se por utilizar as bases Web of Science, Scopus e Ovid, por se tratarem todas de bases multidisciplinares.

$\mathrm{Na}$ terceira etapa foi feito o teste de aderência. Para tanto, pesquisou-se, nas três bases as palavras-chave separadas, refinando a pesquisa pela natureza do recurso desejado: artigos; e também pelo período dos últimos cinco anos, ou seja, de 2010 a 2015. Esta primeira busca, realizada em 16 de maio de 2015 tinha como intuito verificar a relevância do conteúdo recuperado, a partir da leitura de alguns títulos e termos. A quantidade de artigos a seguir (Quadro 2) representa a soma dos trabalhos recuperados nas três bases.

Quadro 2 - Relação das palavras-chave para o teste de aderência.

\begin{tabular}{|c|c|c|}
\hline Eixos & Palavras-chave & $\begin{array}{c}\text { Quantidade de artigos } \\
\text { recuperados }\end{array}$ \\
\hline $1^{\circ}$ & "character design" OR character & 203.605 \\
\hline $2^{\circ}$ & animation & 7.324 \\
\hline $3^{\circ}$ & television OR TV OR "TV seri*" & 34.658 \\
\hline
\end{tabular}

Fonte: Informações organizadas pelos autores. 
Para o teste de aderência no portal CAPES, foi solicitada a busca pelos três eixos de pesquisa, refinando para artigos publicados entre 2010 e 2015 . Após a leitura dos títulos, observou-se a incoerência com os temas de pesquisa.

Quadro 3 - Resultado da busca, a partir da combinação das palavras-chave dos eixos de pesquisa.

Quadro 3 - Resultado da busca, a partir da combinação das palavras-chave dos eixos de pesquisa.

\begin{tabular}{|c|c|c|}
\hline $\begin{array}{l}\text { Combinação } \\
\text { (sintaxe de busca) }\end{array}$ & $\begin{array}{l}\text { Coleções do } \\
\text { Portal Capes }\end{array}$ & $\begin{array}{l}\text { Quantidade de } \\
\text { artigos } \\
\text { recuperados }\end{array}$ \\
\hline \multirow{5}{*}{$\begin{array}{l}\text { ("character design" OR } \\
\text { character AND animation } \\
\text { AND television OR TV OR } \\
\text { "TV seri"") }\end{array}$} & Scopus (Elsevier) & 218 \\
\hline & $\begin{array}{c}\text { Science Citation Index } \\
\text { Expanded } \\
\text { (Web of Science) }\end{array}$ & 196 \\
\hline & One File (GALE) & 119 \\
\hline & $\begin{array}{c}\text { Technology } \\
\text { Research Database }\end{array}$ & 113 \\
\hline & $\begin{array}{l}\text { Advanced Technologies } \\
\text { database with Aerospace }\end{array}$ & 110 \\
\hline
\end{tabular}

Fonte: Informações organizadas pelos autores.

Não se sentiu necessidade de alterar as palavras-chave, mas foi preciso pesquisar diretamente nas bases, por recuperarem mais resultados. As bases eleitas foram a Scopus, Web of Science e Ovid, todas baseadas em seus aspecto multidisciplinar. Nas três buscas, a pesquisa foi refinada por data de publicação (entre os anos de 2010 e 2015) e restrita apenas a artigos com textos completos. Também foram excluídos dos resultados artigos que fossem relacionados às áreas da saúde, ciências sociais, ciências exatas e da terra. O critério de idioma também foi adotado na busca, visando apenas artigos em inglês, português e espanhol. Estas bases reconheceram a sintaxe desenvolvida para a busca (Quadro 4), mas apenas Scopus e Web of Science recuperaram artigos coerentes com o tema, de modo que artigos recuperados pela base Ovid foram excluídos da busca.

Quadro 4 - Resultado da segunda busca a partir da combinação das palavras-chaves dos eixos de pesquisa e dos critérios de refinamento solicitados. 


\begin{tabular}{|l|c|c|}
\hline \multicolumn{1}{|c|}{$\begin{array}{c}\text { Combinação } \\
\text { (sintaxe de busca) }\end{array}$} & Base & $\begin{array}{c}\text { Quantidade de } \\
\text { artigos } \\
\text { recuperados }\end{array}$ \\
\hline $\begin{array}{l}\text { ("character design" OR } \\
\text { character AND animation AND } \\
\text { television OR TV OR "TV } \\
\text { seri*") }\end{array}$ & $\begin{array}{c}\text { Science Citation Index } \\
\text { Expanded } \\
\text { (Web of Science) }\end{array}$ & 398 \\
\cline { 2 - 4 } & Ovid & 6 \\
\hline
\end{tabular}

Depois desta última busca, restaram então 409 artigos para o portfólio bibliográfico bruto. Este material foi reunido no gerenciador Endnote X7. Após a exclusão de artigos duplicados, restaram 403 artigos. Depois do processo de filtragem baseado na leitura dos títulos, foram selecionados 23 artigos considerados coerentes com o tema de pesquisa. Na intenção de potencializar o processo de pesquisa, decidiu-se antecipar a etapa 7, de leitura dos abstracts. Após esta conferência, restaram 3 artigos considerados relevantes para o trabalho.

Na verificação da relevância científica, etapas 5 e 6, não foram encontradas citações nos artigos utilizando-se do sistema de busca do Google Acadêmico; entretanto, por serem todos artigos recentes, de 2013, eles mantiveram-se no portfólio.

A oitava etapa, de descarte dos artigos incompletos, já havia sido realizada, quando as buscas nas bases de dados foram refinadas por "textos completos".

A etapa 9 resultou na formação de um portfólio bibliográfico composto por três artigos, conforme o Quadro 5.

Quadro 5 - Portfólio bibliográfico resultante da revisão sistemática

\begin{tabular}{|c|l|l|l|l|}
\hline Artigo & \multicolumn{1}{|c|}{ Autores } & \multicolumn{1}{|c|}{ Título } & \multicolumn{1}{c|}{ Periódico } & Ano \\
\hline 1 & $\begin{array}{l}\text { AHMED, S.; } \\
\text { WAHAB, J. A. }\end{array}$ & $\begin{array}{l}\text { Animation and } \\
\text { Socialization Process: } \\
\text { Gender Role Portrayal on } \\
\text { Cartoon Network }\end{array}$ & $\begin{array}{l}\text { Asian Social } \\
\text { Science }\end{array}$ & 2013 \\
\hline 2 & $\begin{array}{l}\text { MÍNGUEZ- } \\
\text { LÓPEZ, Xavier }\end{array}$ & $\begin{array}{l}\text { Folktales and Other } \\
\text { References in Toriyama's } \\
\text { Dragon Ball }\end{array}$ & $\begin{array}{l}\text { Animation } \\
\text { Interdisciplinary } \\
\text { Journal }\end{array}$ & 2013 \\
\hline 3 & $\begin{array}{l}\text { BALTEIRO, } \\
\text { Isabel }\end{array}$ & $\begin{array}{l}\text { Blending in English } \\
\text { Charactoons }\end{array}$ & English Studies & 2013 \\
\hline
\end{tabular}

Fonte: Informações organizadas pelos autores. 
Os três artigos foram lidos e analisados, sendo possível apresentar suas ideias essenciais e como eles podem contribuir para o melhor desenvolvimento de personagens que agradem e engajem o espectador em uma série animada, como se vê a seguir.

No artigo intitulado "Animation and Socialization Process: Gender Role Portrayal on Cartoon Network" (2013), Ahmed e Wahab fazem uma análise dos estereótipos utilizados na criação de personagens das séries animadas mais populares no canal de TV especializado em animações, Cartoon Network. São analisadas a ocorrência de personagens masculinos e femininos dentre os personagens principais das séries, bem como os traços psicológicos e visuais com os quais estes personagens são retratados. Esta análise pode contribuir com objetivo de pesquisa no sentido de oferecer base teórica a respeito dos cânones atualmente utilizados na concepção de personagens de algumas das séries de TV que possuem maior alcance mundial, agregando a quantidade de informações já levantadas a respeito dos esteriótipos que o character designer deve ter ou não em mente quando está desenvolvendo um personagem.

Em "Folktales and Other References in Toriyama's Dragon Ball" (2013), Mínguez-López analisa a presença de influências do folclore de várias culturas asiáticas na constituição da série de animação japonesa "Dragon Ball", mas também citando outras animações, bem como obras de literatura (romance e quadrinhos) que também fazem uso de aspectos religiosos e mitológicos orientais em suas concepções. Este trabalho pode contribuir à pesquisa no sentido de mostrar como os elementos religiosos, folclóricos e mitológicos de uma cultura podem influenciar o desenvolvimento de personagens nos mais variados graus de profundidade (desde um grau mais intrínseco, conceitual, até a dimensão da aparência); proporcionando um panorama de como essa visão criativa pode ser transposta para a utilização no design de personagens para séries brasileiras.

No artigo "Blending in English Charactoons" (2013), Balteiro trata do aspecto do naming no processo de desenvolvimento de personagens para animações, específicamente nomes que são misturas de palavras, analisando seus aspectos morfológicos, fonológicos e semânticos, concluindo que esse tipo de técnica deixa os nomes mais sonoros, musicais, fáceis de serem decifrados, memoráveis e atrentes. Este artigo contribui para a pesquisa evidenciando o peso que o naming possui no conjunto do personagem, podendo agregar muito à sua receptividade e potencial de ser relembrado - assim como acontece com uma marca - e portanto esse aspecto deve ser considerado no processo de desenvolvimento de personagem.

Uma vez analisado o portfólio bibliográfico resultante da revisão sistemática, foi possível então partir para a exploração empírica de materiais, uma vez que já haviam evidências teóricas encontradas no material reunido no portfólio bibliográfico.

As principais evidências encontradas foram definidas nas seguintes palavras-chave: "socialização", "cultura", "gênero", "aspectos físicos", "aspectos psicológi- 
cos", "folclore", "mitologia", "religião", "arquétipo", "nome", "engajamento", "receptividade", "atraente". Todas estas palavras foram então relacionadas à palavra-chave "personagem" e inseridas em ferramentas de busca online através do site Google e também no sistema online de biblioteca da Universidade Federal de Santa Catarina.

Sentiu-se a necessidade de procurar material mais técnico a respeito do processo de design de personagens no todo de um projeto de animação, de modo que foram inseridas novamente as palavras "animação", "série" e "televisão". Também foram inclusas as palavras "projeto" e "produção".

Quanto a seleção dos materiais pesquisados, optou-se por restringir a pesquisa empírica a conteúdos em inglês e português, de modo que as versões em inglês de todas as palavras-chave foram também buscadas: socialization, culture, genre, physical aspects, psychological aspects, folklore, mythology, religion, archetype, name, naming, engagement, receptivity, attractive, character, animation, serie, television, project, production. Dado o grande universo de retornos desta pesquisa e da inviabilidade de tempo para analisar todos os resultados, restringiu-se o exame apenas à livros. Ainda assim, a análise deste conteúdo foi extensa, de modo que outros meios de seleção empíricos foram adotados para restringir os resultados, baseados na repetição de temas, relevância dos autores, data de publicação e ineditismo do conteúdo. Ao fim deste processo seletivo, restaram 12 livros, listados no Quadro 5.

Quadro 6 - Portfólio bibliográfico resultante da exploração empírica

\begin{tabular}{|c|c|c|c|}
\hline Livro & Autores & Título & Ano \\
\hline 1 & WHITE, Tony & Animation from Pencils to Pixels & 2006 \\
\hline 2 & BLAIR, Preston & Cartoon Animation & 1994 \\
\hline 3 & $\begin{array}{l}\text { FARIA, Mônica Lima } \\
\text { de }\end{array}$ & $\begin{array}{l}\text { Imagem e Imaginário dos Vilões } \\
\text { Contemporâneos }\end{array}$ & 2013 \\
\hline 4 & $\begin{array}{l}\text { STANCHFIELD, } \\
\text { Walt }\end{array}$ & Gesture Drawing for Animation & - \\
\hline 5 & TODOROV, Tzvetan & Introdução à Literatura Fantástica & 2008 \\
\hline 6 & $\begin{array}{l}\text { ISBISTER, } \\
\text { Katherine }\end{array}$ & $\begin{array}{l}\text { Better Game Characters by Design } \\
\text { - A Psychological Approach }\end{array}$ & 2006 \\
\hline 7 & WEBSTER, Chris & Animation - The Mechanics of Motion & 2006 \\
\hline 8 & INCE, Steve & Writing for Video Games & 2006 \\
\hline 9 & SEGER, Linda & Como Criar Personagens Inesquecíveis & 2006 \\
\hline 10 & NESTERIUK, Sergio & Dramaturgia de Série de Animação & 2011 \\
\hline 11 & CAMPBEL, Joseph & O Heroi de Mil Faces & 1995 \\
\hline 12 & JUNG, Carl G. & Os Arquétipos e o Inconsciente Coletivo & 2011 \\
\hline
\end{tabular}


Da mesma maneira que com os artigos, os livros selecionados também foram analisados, sendo apresentado a seguir como eles podem contribuir para a pesquisa.

O livro "Animation From Pencils to Pixels" (2006) de Tony White relata minuciosamente as etapas do processo de produção de uma animação, dos conceitos básicos da história até a distribuição, abordando também questões como direitos de uso e copyright. No segundo capítulo, White aborda o design de personagens, dando um patamar histórico-técnico de como as tecnologias 2D e 3D de animação impactam o personagem, mas também abordando questões conceituais mais inclinadas aos aspectos visuais do personagem, que devem ser levados em conta na pesquisa, como o estilo de desenho, formas, proporções, cores e alturas.

O segundo livro, "Cartoon Animation" (1994) de Preston Blair, apesar de antigo, é bastante relevante. Apesar de focado amplamente nos aspectos visuais, apresenta uma série de tipologias relacionando personalidades de personagens com estereotipos físicos. Esta análise de Blair é considerada pelos autores deste artigo fundamental por estabelecer uma semântica relacionando traços visuais dos personagens com seus aspectos psicológicos.

Em “Imagem e Imaginário dos Vilões Contemporâneos" (2013), Faria apresenta uma análise profunda do conceito do vilão, mostrando em que ele diferencia-se do heroi ou do anti-heroi. Sua contribuição para a pesquisa é grande, uma vez que os vilões são personagens tão marcantes quanto os mocinhos em uma série de animação.

Não foi possível precisar a data em que o livro "Gesture Drawing for Animation" foi publicado, uma vez que ele chegou a público através da internet. Neste material, bastante ligado ao desenho em si, Stanchfield discorre sobre a expressão gestual, corporal e de traço do personagem como forma de narrativa.

"Introdução à Literatura Fantástica" (2008) é um livro sobre os gêneros literários advindos (ou que formam) a fantasia. É interessante à pesquisa porque Todorov define três condições para a existência da fantasia: a hesitação entre o natural e o sobrenatural, a escolha entre vários modos ou níveis de leitura e os personagens, como chave de identificação do leitor com a obra. Acredita-se que é possível fazer a transposição do leitor do livro para o espectador da TV na pesquisa, visando estabelecer um parâmetro entre a identificação leitor-personagem com a mesma situação entre o espectador-personagem.

Como o próprio nome denuncia em "Better Game Characters by Design - A Psychological Approach" (2006), Isbister traz uma abordagem psicológica do desenvolvimento de personagens. Apesar de pensado para o desenvolvimento de personagens para jogos, acredita-se que é possível transpôr estes conceitos do jogador para o espectador, da mesma forma que com o livro citado no parágrafo anterior. 
O livro "Animation - The Mechanics of Motion" (2006), de Webster, assemelha-se com o de White (2006) em seu propósito, porém não é tão bem estruturado. Apesar disso, ele é mais minucioso: embora não haja um capítulo específico dedicado aos personagens, eles são tratados, de forma conceitual e técnica em vários momentos da obra; e para situações bastante específicas, como a diferenciação entre o personagem humano e o não-humano do ponto de vista da animação destes elementos em si mas também de sua caracterização.

"Writing for Video Games" (2006), é um livro sobre roteiros para jogos, mas que trata de muitos aspectos relevantes para se levar em conta nos personagens como seus pontos de vista, construção de diálogos coerentes às suas personalidades, conflitos e motivações. Da mesma maneira que no livro de Isbister (2006), acredita-se que a abordagem de Ince abordagem sobre personagens para games possa ser transposta para personagens de animação.

Se o livro anterior aborda os conceitos que geram a motivação de um personagem, em "Como criar Personagens Inesquecíveis" (2006), Seger aprofunda detalhadamente os aspectos que podem formar seu perfil psicológico. Este é um livro focado em personagens para TV em geral, não necessariamente apenas para animação; então os aspectos visuais são aqui tratados muito brevemente, servindo como elementos de apoio para os elementos da psiquê.

"Dramaturgia de Série de Animação" (2011) de Nesteriuk é um livro considerado essencial para a pesquisa. Nele é feito um resgate histórico da animação de seus primórdios até sua chegada na televisão. Em um segundo momento, o autor caracteriza os elementos das séries animadas, em específico para a televisão, realizando em seguida, um resgate histórico da experiência brasileira na área, buscando relacioná-la com séries de amplo conhecimento mundial. Em seguida, este livro também apresenta minuciosamente todos os processos e etapas necessárias para a produção, financiamento e veiculação de uma série animada. Em um próximo momento, são analisadas duas séries de animação brasileiras que na época de publicação do livro, haviam sido recém-lançadas: "Tromba Trem" e "Carrapatos e Catapultas". Por fim, o livro disponibiliza uma extensa lista bibliográfica dos materiais consultados para sua concepção.

Em "O Heroi de Mil Faces" (2008), Campbell, baseado em seus estudos de mitologia comparada, apresenta o conceito da Jornada do Heroi, ou Monomito; a estrutura narrativa mais comum nas histórias mitológicas, amplamente utilizada em narrativas de todas as mídias. Esse livro, em conjunto com o de Jung (2011), é essencial para entender as estruturas basilares que formam um personagem e surgem antes mesmo de sua psiquê.

Em "Os Arquétipos e o Inconsciente Coletivo" (2011), Jung apresenta o conceito de arquétipos, ideias primordiais presentes no inconsciente coletivo da humanidade, formadora de todas as representações mitológicas e, antes disso, estruturante 
da psiquê humana, sendo aquilo que as ideias são antes de possuírem símbolos que as representem. Entender estes conceitos é entender a formação da estrutura do inconsciente humano pré-significação; e habilita o projetista a usar os personagens como símbolos para significar estes conceitos.

\section{Conclusões}

Os procedimentos e resultados da pesquisa que gerou esta revisão integrativa mostram-se claros, objetivos e criteriosos, o que possibilita sua replicação e atualização posterior. No que diz respeito aos resultados, os artigos e livros coletados apresentam conteúdos correlatos e fundamentais para o desenvolvimento de um corpo teórico que contribua para uma pesquisa sobre a produção de design de personagens para séries animadas de TV, conforme os critérios deste trabalho, de modo que, ao retomar a questão proposta no início deste artigo, "Quais os conhecimentos necessários para realizar o desenvolvimento de personagens que integrem os atributos de agradabilidade e engajamento à narrativa, favorecendo o envolvimento do espectador com a série animada para TV?", consideram-se satisfatórias as contribuições levantadas.

O mercado de animação brasileira em franca expansão e os incentivos por parte de organizações públicas e privadas justificam a importância desta pesquisa. Espera-se, com este trabalho, cooperar com futuros estudos na área de desenvolvimento de personagens, colaborando para o crescimento do setor de animação no país.

\section{Referências}

FONSO, Michele H. F. Et al. Como construir conhecimento sobre o tema de pesquisa? Aplicação do processo ProKnow-C na busca de literatura sobre avaliação do desenvolvimento sustentável. Revista de Gestão Social e Ambiental - RGSA, São Paulo, v. 5, n. 2, p. 47-62, 2011.

ASSOCIAÇÃO BRASILEIRA DE LICENCIAMENTO (ABRAL). O Setor.

Disponível em: <http://abral.org.br/o-setor/>. Acesso em 13 de maio de 2015.

BALTEIRO, Isabel. Blending in English Charactoons. English Studies v. 94.8, 2013.

BLAIR, Preston. Cartoon Animation. Lake Forest: Walter Foster Publishing, 1994.

CAMPBEL, Joseph. O Heroi de Mil Faces. São Paulo: Editora Pensamento, 1995.

COORDENAÇÃO DE APERFEIÇOAMENTO DE PESSOAL DE NÍVEL SUPERIOR (CAPES). Misão e Objetivos. Disponível em:

<http://www-periodicos-capes-gov-br.ez46.periodicos.capes.gov.br/index. php?option=com_pcontent\&view=pcontent\&alias $=$ missao-objetivos $\&$ Itemid $=102>$. Acesso em 16 de maio de 2015. 
FARIA, Mônica Lima de. Imagem e Imaginário dos Vilões Contemporâneos. Pelotas: Editora UFPEL, 2013.

INCE, Steve. Writing for Video Games. London: A\&C Black, 2006.

ISBISTER, Katherine. Better Game Characters by Design - A Psychological Approach. San Francisco: Elsevier, 2006.

JUNG, Carl G. Os Arquétipos e o Inconsciente Coletivo. Rio de Janeiro: Editora Vozes, 2011.

MÍNGUEZ-LÓPEZ, Xavier. Folktales and Other References in Toriyama's Dragon Ball. Animation, v. 9.1, p. 27-46, 2013.

NESTERIUK, Sergio. Dramaturgia de Série de Animação. São Paulo: Sergio Nesteriuk, 2011.

PRODANOV, Cleber Cristiano; FREITAS, Ernani Cesar. Metodologia do Trabalho Científico: Métodos e Técnicas da Pesquisa e do Trabalho Acadêmico. Novo Hamburgo: Feevale, 2013. Disponível em: <http://www.feevale.br/Comum/midias/8807f05a-14d0-4d5b-b1ad-1538f3aef538/E-book\%20Metodologia\%20do\%20Trabalho\%20 Cientifico.pdf>. Acesso em 16 de maio de 2015.

SEGER, Linda. Como Criar Personagens Inesquecíveis. Rio de Janeiro: Bossa Nova, 2006.

SHUMAILA, Ahmed; WAHAB, Juliana Abdul. Animation and Socialization Process: Gender Role Portrayal on Cartoon Network. Asian Social Science v. 10.3, p. 44, 2013. 